sions that I ask you to find room in your pages for this short protest.

Middle Class Schools, I.ittlehampton, January I3

\section{A Solar Halo}

A PHENOMENON quite unusual in these parts was witnessed here this morning in the form of a solar halo of surpassing brilliancy. The outer ring was dazzling white; the next pale lemon, the inner orange, and the inclosed space grayish brown, uniform throughout. The display was brightest at sunrise. The sky was clear with the exception of a few light clouds along the eastern horizon. The air was still. The temperature was ten degrees below freezing point. As the sun climbed higher the colours gradually faded out, until at 10.30 the last traces had disappeared.

Mansfield, Pa., U.S.A., January Io

\section{Coltsfoot}

THERE is an interesting article on "Coltsfoot" in the Pall Mall for January 21, in which mention is made of fifty-two species of wild flowers being in bloom at Lyme Regis; "and at Hastings nearly one hundred have been counted within a semicircular radius of ro miles." Coltsfoot is amongst the flowers already in blossom on the south coast ; and it is instanced as a very remarkable proof of the mildness of this winter. I think it is nearly as wonderful that Corylus avellana, the common nut, should be in blossom on a sheltered bank in North Wiltshire. Not only are the catkins fully in blow, but the fertile flowers are also in blos:om, and that not only on one, but on many bushes. A wood full of primroses such as we often wait for till March or April is another instance of absence of frost.

Salthrop, Wroughton, Wilts., January 23 T. S. MASKELYNE

\section{The Absolute Sine Electrometer}

IN my paper in last week's NATURE (p. 278), read " $\frac{1}{60}$ inch pitch" instead of " $\frac{1}{16}$ inch pitch" for the micrometer screw. The diagram has been turned round counterclockwise.

Cooper's Hill, January 21 George M. Minchin

PEDiculi. - A correspondent asks if any one can inform him whether in experimental researches on spontaneous generation pediculi have ever been the subjects of observation, and if so, with what results? Further, is it likely that the density of their dermal structures affords them a means of resistance to heat applied through a liquid medium?

\section{PHYSICAL NOTES}

DR. R. KöNIG has recently described a method of investigating the nodes in the vibrating column of air in an organ-pipe. The pipe-a large one-is laid horizontally on its back, and a long slit is made the whole length of the pipe. The slit is closed by water, the pipe lying in a trough. A small curved tube, open at the end, passes down through the water and up through the slit into the pipe. Its other end is joined to a manometric capsule in conjunction with a flame apparatus of the usual type. The nodal surfaces can be determined to within two millimetres. The introduction of the tube interferes less with the conditions of vibration than the introduction of a tissue-paper disk or other explorer hitherto $u$ ed.

A NEW barometer, automatically recording the variations on an enlarged scale, has been iavented by Marshall Delaey (Bull. Belg. Acad., No. 8). It has the following arrangement:-The barometric tube, having a capacious reservoir at top, is fixedly suspended. The cistern is a tube slightly wider and nearly as long; it bears on oxe side an index, and on the other a pencil working on a moving cylindrical surface, and it forms the upper part of a kind of areometer, having a downward extension in the form of a closed tube floating in mercury in a wider tube, which communicates below, through a U-tube, with a wide and shallow covered cistern, the level in which is approximately constant. The variation of pressure is marked by the variation of the height of mercury in the reservoir, and this latter is to that of the total height in the barometric cistern (or to the path of the float or of the pencil) in the ratio of the section of the cistern to that of the reservoir (a sixth in the instrument the author represents). Thus an a.mplification is realised.
THE colourless fluorspar of Switzerland, according to $\mathbf{M}$. Cornu (Four. de Phys., October), is a substance at least as tr insparent for ultra-violet rays as quartz, and its law of dispersion is so much in harmony with that of quartz that with the two a system of lenses of nearly perfect achromatism may be had. To give an idea of this achromatism M. Cornu states that he obtains on one clické, with very satisfactory distinctness, the spectrum of all the photographic lines of metals, from the three blue lines of zinc to the lines No. 32 of aluminium. With such objectives a determination of the wave-lengths of very refrangible radiations becomes possible. The author describes measurements of $t$ is kind (along with details of method) in the case of magnesium, cadmium, zinc, and aluminium.

A RHEOMETER, for measuring currents at different depths in water, is described by Signor Scardona in the Rivista Scientifico. Industriale (September 30). It acts by pulses generated at intervals (according to the speed of the current) in a tube, and affecting a bell. The water-current acts on two screw-vanes on a horizontal shaft in a case attached to a vertical rod. This shaft (which a flat vane keeps in a line with the current) actuates, at intervals, through an endless screw and a reducing system of wheels, a lever applied to a caoutchouc capsule at the end of a metallic tube, through which, and a flexible tube attached, the resulting pulses pass to the bell-arrangement (which is in a portable case). The rod and the metallic tube are each made up of several pieces screwed together, and the vane case and tube can be fixed at any part of the rod. The advantages claimed over Amsler's rheometer are simplicity (in dispensing with electrical action), and a better kind of signal (one stroke of the bell for each turn of a wheel).

AN experimental inquiry by Herr Graetz (Wied. Ann. No. Io) into the heat-conductivity of gases and its relation to temperature results as follows:-I. Heat-conduction in the gases air, hydrogen, and (with low temperatures) carbonic acid, consists in transference of progressive energy only; intramolecular energy contributes immeasurably little. The molecules thus behave like material points. 2. The relation of heat conduction to temperature is found by experiment to be such (approximately) as Clausius' theory requires. 3. All results for gases and vapours, showing divergences from the values calculated from theory, are without evidential force, for they only gave the apparent heatconducting power, in consequence of absorntion of radiant heat. 4. The divergence of the temperature-coefficient of friction from that calculated from theory cannot have for cause (or not alone) the decrease of the molecular diameter with rising temperature; some other explanation must be sought.

A USEFUL Comparison of the numerous determinations of the expansion of water by heat is made by Herr Volkmann in a paper contributed to Königsberg Institute (Wied. Ann. No. IO). Experimenters, it is known, have used two methods-the hydrostatic and the dilatometric. The author gives in a table the average values for volume and density of water (deduced from the observations of Hagen, Matthiessen, Pierre, Kopp, and Jolly) for all temperatures from zero to $25^{\circ}$; also the volumes every $5^{\circ}$ from $25^{\circ}$ up to $100^{\circ}$. The temperature of greatest density of vater is, according to the best data, $+3^{\circ} 94^{\circ} \mathrm{C}$. Herr Volkmamn thinks there is no occasion to study the subject anew on the lines hitherto adopted; but it might be well (in his opinion) to observe the absolute expansion of water in the same way as Regnault determined that of mercury (with communicating tubes).

IN view of assertions that the band-spectrum attributed to hydrogen by Herr. Wiillner is really that of a hydrocarbonacetylene according to Herr Ciamician-the former physicist has made a careful examination of the acetylene spectrum (Wied. Ann. No. 10), and finds that, as might be expected from the higher proportion of carbon in acetylene, its spectrum differs from that of hydrogen much more than do the spectra of ethylene and marsh gas. While in these latter the characteristic carbon bands indicate the spectrum to be that of a carbon-containing gas, the whole of the red, orange, and yellow part, in the other, resembles much more the spectrum of carbonic acid than it does that of hydrogen.

THE physical properties of indium have been very little known hitherto. A recent contribution on the subject by Herr Erhard (Wied. Ann. No. I I) treats of some of its electric properties. As regards resistance, he finds that indium is like some other metals in not coming under the often-accepted-rule that pure metals have a change of coefficient of resistance with tempera- 
ture corresponding to the absolute temperature. The thermoelectric position of iridium among seven other metals for temperature-differences $0^{\circ}$ and $98^{\circ} \cdot 6$ is thus indicated-

$$
\text { - Al, } \mathrm{S} \text {, } \mathrm{In}, \mathrm{Zn}, \mathrm{Ag}, \mathrm{Au}, \mathrm{Cu}, \mathrm{Fe}+
$$

with smaller differences $\left(0^{\circ}\right.$ and $5^{\circ}$ or $\left.10^{\circ}\right)$ it comes after $\mathrm{Au} \mathrm{Zn}$. Once more, elements were constituted of indium in its chloride with zinc, copper, and iron in their chlorides, and examined. In the element indium-zinc, the indium is the positive pole; in the two others the negative. The electromotive force of $\mathrm{In} / \mathrm{Zn}$ was found equal to $0.33 \mathrm{I}$ Daniell ; of $\mathrm{Fe} / \mathrm{In}=0.160 \mathrm{D}$., and of $\mathrm{Cu} / \mathrm{In}=0.584 \mathrm{D}$.

In a paper communicated to the American Association for the Advancement of Science Dr. E. L. Nichols discusses the relation between the electric resistance of platinum and its coefficient of expansion by heat. He has made careful experiments by an ingenious method at $t \in$ mperatures rising up to $3000^{\circ} \mathrm{C}$, and finds that all the empirical formulæ given previously by Siemens, Matthiesen, and Benoit are unreliable, and, from certain anomalies in the behaviour of the metal he concludes that it is safer to infer the temperature from its expansion than from its electric resistance.

TORNADOES, WHIRLWINDS, WATERSPOUTS, AND HAILSTORMS ${ }^{1}$

II.

THE Dust Storm of India and other dry, hot climates, is another well-marked type of the whirlwind. The observations and illustrations of these meteors, which have been made by Baddeley and others, are in a high degree instructive from the light they throw on the actual movements of the whirlwind which the dust-laden aircurrents of the storm present in a visible form to the eye.

Previous to the outbreak of a dust storm, the atmosphere is unusually calm and sultry, thus essentially resembling the conditions of weather under which the tornado and whirlwind originate and which point to a vertical disturbance in the equilibrium of the atmosphere. The simplest form of the dust storm is that of a tall aërial column of sand moving onwards, and drawing into itself as it whirls round in its course, dust and other light bodies within the sweep of the strong air-currents which blow along the surface and converge vorticosely round the base of the column. A frequent form is shown in Fig. 4, which represents several dust columns grouped together, each whirling independently round its own axis with incurving air-currents at the base, whilst the group is bodily borne forward, presenting remarkably striking aspects as the forms and relative positions of the columns are changed. While engaged early in $185 \mathrm{I}$ in the investigation of dust storms, Dr. Baddeley followed one on horseback, and was fortunate to note several of the important phenomena of these storms. As the dust storm passed various objects in its course, such as tents, horses, \&c., it gradually diminished in size, till instead of a whirling circle of five or six feet in diameter, composed of several rotating eddies, or spirals of dust, such as are seen in Fig. 4, it terminated in a single cone, the apex of which in contact with the ground, rotated briskly from left to right, just as the whirling composite circle had done. From the cone of dust, a long ribbon-like band about a foot across, of equal dimensions throughout, extended into the atmosphere as far as the eye could see, but as its sides presented a greater opacity than the central portion it was really of a cylindrical form. This column was rendered visible by the dust it had whirled aloft, and was further observed to exhibit by the light of the sun which shone through it, a kind of vermicular spiral motion. Aloft the column extended forwards in advance of the whirling cone. Suddenly the lower portion of the column which continued to rotate to the last vanished, and the upper portion then slowly receded upwards and onwards till it passed out of sight.

The important character of the evidence adduced by ${ }^{1}$ Continued from p. 157 . the observations of dust storms towards a correct understanding of the whirlwind consists in the circumstance that it affords conclusive evidence that there is a strong inflow of the air along the surface of the ground all round vorticosely towards the base of the whirlwind, and that these same inflowing air-currents thereafter ascend through the air along the centre of the whirlwind, carrying with them the evidence of their ascent in the visible solid particles of dust, sand, and other light objects they whirl up with them in their upward course.

The most marked difference between the dust storm and the waterspout or tornado lies in the essential difference, as regards moisture, of the masses of air which are drawn into and ascend the columns of the whirlwinds. In the waterspout, certainly in all waterspouts that reach down to the surface of the earth, the earth is at, or not far from, the point of saturation, and in these cases the whirlwind is accompanied with heavy rains. In some instances the rainfall has been so excessive that it can fittingly be described as only an aërial torrent of solid water, that from the velocity with which it falls from the clouds digs

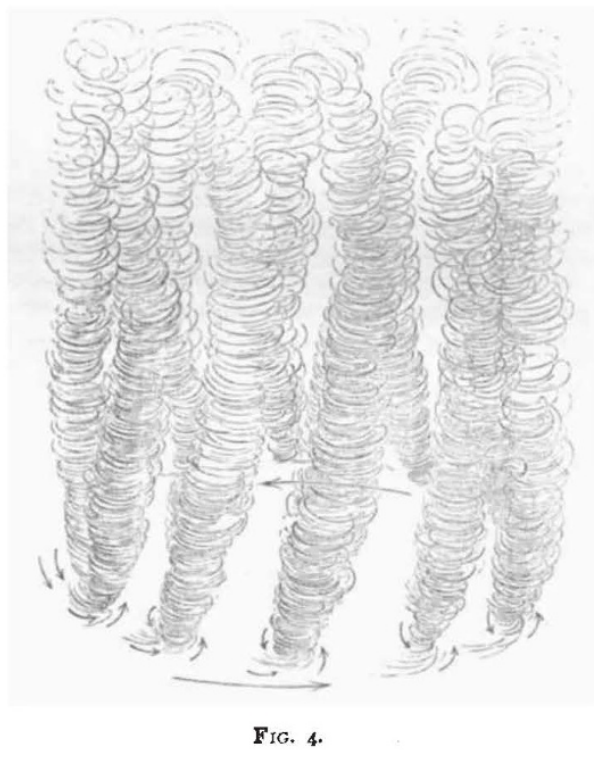

deep openings in the soil at the points where it strikes the ground. Thus immediately after the great tornado which occurred in Pennsylvania in June, I838, Espy visited the spot and carefully examined the sides of the ridges and mountains on which its chief force was spent. He found many holes dug out by the torrents of water shot dow $n$ by that tornado, which measured about thirty feet in diameter and from three to six feet deep, according to the nature of the soil and depth of the rock; the sides of the holes being in most cases cut down almost perpendicularly on their upper side, but entirely washed out on their lower side, so as to form the commencement of a ravine.

Cn the other hand, the air-currents which enter into and rise through the columns of the dust storm are very dry, and far removed from the point of saturation. Hence a large number of dust storms are neither accompanied nor followed by rain or any aqueous precipitation. Not a few, however, are observed to be followed towards the close of the storm with a sudden fall of rain, occasionally little more than a sprinkling, which may be due either to the condensation caused by the extreme rarefaction resulting from the rapidity of movement of the gyrations of the ascending air-currents, or to the great height in the atmosphere to which the air-currents are carried by the storm. 